\title{
Top 10 CUAJ peer-reviewers of 2016!
}

Cite as: Can Urol Assoc J 2016;10(11-12):371. http://dx.doi.org/10.5489/cuaj.4259

A s a peer-reviewed publication, Canadian Urological Association Journal unbiased, critical reviews - ensuring we continue to publish the highest-quality material. While we want to take this opportunity to thank all who have contributed to the journal this past year, we would like to highlight the following individuals. They have been called upon frequently and have continuously provided timely, in-depth assessments.

\section{Our top 10 peer-reviewers of 2016 are:}

Dr. Rahul Bansal, McMaster Institute of Urology, Hamilton, ON, Canada Dr. Dimitri Barski, Lukas Hospital Neuss, Germany

Dr. Bimal Bhindi, University Health Network, University of Toronto, Toronto, ON, Canada

Dr. Peter Black, University of British Columbia, Vancouver, BC, Canada Dr. Rodney Breau, University of Ottawa, Ottawa, ON, Canada

Dr. Ilias Cagiannos, University of Ottawa, Ottawa, ON, Canada

Dr. Joseph Chin, Western University, London, ON, Canada

Dr. Trevor Flood, Ottawa Hospital, Ottawa, ON, Canada

Dr. Dragos Georgescu, St. John Clinical Emergency Hospital, Bucharest, Romania

Dr. Kevin Zorn, University of Montreal Hospital Centre, Montreal, QC, Canada

If you would like to see your name on this list next year and are not yet registered as a reviewer for the journal, please contact us at journal@cua.org. 